Portland State University

PDXScholar

$10-1-2015$

\title{
Heard on the Net: Three Lightning Interviews with the Principals Involved with Advancing Research Communication \& Scholarship, Open Library of Humanities, and The One Repo
}

Jill Emery

Portland State University, jemery@pdx.edu

Follow this and additional works at: https://pdxscholar.library.pdx.edu/ulib_fac

Part of the Scholarly Communication Commons, and the Scholarly Publishing Commons Let us know how access to this document benefits you.

\section{Citation Details}

Emery, Jill (2016). Heard on the Net: Three Lightning Interviews with the Principals Involved with Advancing Research Communication \& Scholarship, Open Library of Humanities, and The One Repo. The Charleston Advisor, Volume 17, Number 2, pp. 51-53.

This Article is brought to you for free and open access. It has been accepted for inclusion in Library Faculty Publications and Presentations by an authorized administrator of PDXScholar. Please contact us if we can make this document more accessible: pdxscholar@pdx.edu. 


\section{Three Lightning Interviews with the Principals Involved with Advancing Research Communication \& Scholarship, Open Library of Humanities, and The One Repo}

doi:10.5260/chara.17.2.51

By Jill Emery (Collection Development Librarian, Portland State University)

<Jjemery@pdx.edu>

$F_{c}^{o m}$ or this column, I've conducted three mini-interviews with Robin Champieux from Advancing Research Communication \& Scholarship, Martin Eve from Open Library of Humanities, and Mike Taylor from The Open Repo to provide information regarding each of their projects. All three are aimed at changing the current scholarly communications landscape and finding new ways to support and sustain scholarly information.

\section{Advancing Research Communication \& Scholarship (ARCS)}

\section{<http://commons.pacificu.edu/arcs/about.html>}

Robin Champieux is the Scholarly Communications Librarian at Oregon Health \& Science University in Portland, Oregon. In 2015, Robin, along with an advisory board, launched Advancing Research Communication \& Scholarship (ARCS). The goal of this project is to engage the diverse communities involved in the scholarship and practice of research communication to examine the current scholarly communication landscape, build collaborations, and affect change. This engagement focuses on early career researchers/scholars to see how new and different forms of scholarly communication can be built and developed. The initial event was a face-to-face conference held in April 2015 in Philadelphia, PA. The second initiative has been an online contest and showcase highlighting the rewards of open scholarship. Following is the lightning interview with Robin about ARCS.

What motivated you to try to develop something beyond librarianoriented meetings?

I wanted to build a forum that reflected and engaged the multiple communities and issues involved in scholarly production and communication, because, very honestly, I wasn't getting all I needed from library meetings to do my job, which is to understand and affect scientific communication locally and globally. This is not to say that community specific conferences are not valuable, but supporting and improving knowledge communication in the digital age involves activities and collaborations across many organizations, disciplines, and expertise. Moreover, I was also interested in broadening existing and potential understandings of how libraries and librarians affect scholarly communication, both within and outside of our community.

\section{What has ARCS done up to this point?}

ARCS held its inaugural meeting in April of this year. We hosted nearly 200 attendees, including 30 student and early career researcher scholarship attendees. Sessions included thoughtful investigations into the future of peer review, global perspectives on scholarly communication, data sharing in the humanities, funder perspectives on research impact, and blogging as a form of scholarly communication, to name a few. The ability to hear from and engage with librarians, scholars, scientists, funders, publishers, and technologists was applauded by our attendees and speakers. Additionally, we are partnering with the Winnower on a contest to showcase and reward stories about successful open scholarship. This project was an outcome of the ARCS Early Career Researcher Workshop, and the contest winners will be announced during Open Access Week 2015.

\section{What are you most proud of in regards to ARCS?}

There are several things that make me proud. As noted above, we achieved our goal of bringing together and engaging a diverse group of stakeholders. I'm also proud of the quality and richness of our programs. Our advisory board, session organizers, speakers, and attendees facilitated and contributed to discussions that delved deep and tackled difficult questions. Finally, I am immensely pleased that with the support of our scholarship sponsors, PLoS, BioMed Central, PeerJ, and Springer Open, we were able to host so many students and early career researchers. Building on these successes is driving our planning for ARCS 2016.

What excites you most about the engagement with early career researchers/scholars?

Sadly, most of the early career scientists and scholars I know are not encouraged or supported to critically think about the effects of how they communicate their research. I'm passionate about filling that gap, and believe the rewards can be dramatic. The transition to open science and scholarship is in part, cultural. In this sense, I think students and early career researchers can be powerful advocates, and have some of the best ideas and skills for improving scholarly communication. The ARCS team hopes to increase our activities and support in this area moving forward.

Do you think ARCS can maintain a balance between humanists and scientists?

Yes, and being mindful of this will be essential to our success and relevance moving forward. We don't have a blueprint, but I think two strategies are essential. First, we need to ensure we're engaging both communities in the make-up of our advisory board, session organizers, and conference speakers. Second, it's important to support the investigation of seemingly discipline specific issues, through specialized workshops and sessions. I believe that providing a forum wherein attendees can zoom in on certain topics ultimately stimulates more 
lively and novel conversations during the cross-disciplinary sessions and social events.

\section{Open Library of Humanities (OLH) <https://www.openlibhums.org/>}

Martin Eve is one of the academic Project Directors of the Open Library of Humanities (OLH) along with Caroline Edwards. Martin is a Senior Lecturer in Literature, Technology and Publishing at Birkbeck University in London. The Open Library of the Humanities was launched in 2013 to help address the needs of providing an approach for academics in the humanities to provide quality content that is openly available. The intent of OLH is to provide a gold Open Access, peer-reviewed, internationally supported, academic-led, not-for-profit, mega journal, multi-journal, and books platform for the humanities. Currently, Martin has been fundraising through a library partnership model to support this ambitious goal and to make it sustainable. OLH is set to launch seven journals and most recently gained formal charitable status recognition by the British government. Following is the lightning interview with Martin about OLH.

OLH recently announced obtaining formal charitable status in the U.K., can you address how this is beneficial to the project?

OLH has always had a not-for-profit mission. I don't believe that profit-driven academic publishing is the best way to address the systemic economic problems in our system that is supposed to be about the dissemination of knowledge (hyperinflationary cost increases, access gaps, lack of re-usability etc.) Charitable status allows us to formally encode the fact that OLH exists solely for the public benefit and not for any profitable motive. Of course, it also comes with some economic advantages; we do not have to pay corporation tax. The charitable objects of the Open Library of Humanities are now formalized as "the advancement of education for the public benefit by publishing Open Access, high quality, educational, original, academic research material in particular, but not exclusively, in the humanities and social-scientific disciplines." We define Open Access as "the online publication of material for which there is no charge to readers," with open licensing desirable and recommended by default.

OLH appears to be gathering quite a bit of support among libraries in North America and in the U.K. Do you have plans to develop support from libraries worldwide?

Indeed! A large part of the Mellon grant that we were awarded earlier this year is to scale the economic model. With every library that joins, the cost-per-article-per-institution is lowered. We plan to develop a comprehensive worldwide outreach programme over the next few years. This will be coupled with work on multi-lingual publishing and annotation/translation functionality. In this way, we plan to make the OLH a truly global and inclusive platform.

To date, there are seven journals that will be launched in 2015, do you have others in the pipeline to announce in 2016?

After launch this month (September 2015), new journals that wish to join the platform must seek sanction from our academic board and the supporting libraries. The first vote is anticipated to take place in November. We have already two new subscription journals lined up for a potential flip at that point (although I can't name them yet).

\section{What are you most proud of at this point with OLH?}

I'm very proud that we've got so many institutions of all shapes and sizes to commit to a novel funding mechanism for journals in the humanities that, I believe, addresses the concerns of most humanists about an author-pays model. I don't really want to herald the "success" of the platform yet, though, or come across as overly proud. There's still a huge amount of work to be done. When we go live with seven journals this month, it is just the beginning. To feel proud about what we've achieved is one thing, but I'd prefer to think about what we still need to do. In particular, we need to show to supporting libraries how this will scale at an affordable, incremental rate, demonstrating viable offsetting against subscriptions. I'm sure we can do it. If that works over the next five years and if institutions continue to support the model, ask me again then and I might feel proud!

Can you talk about how you plan to engage early career researchers through the OLH project?

We are acutely aware of the systemic pressure placed upon ECRs to publish in prestigious venues, even when their instincts might push them to new Open Access venues (indeed, I feel this pressure institutionally myself). Our plan to flip existing subscription publications is part of this engagement, though. We want to change the system so that there is no conflict between publishing in a place that is good for an ECR's career and a place that is openly accessible. Beyond that, we have an ECR committee that we will continue to engage with and seek advice on the ways in which we can support early career researchers.

\section{Repository: The One Repo <http://blog.onerepo.net/>}

Launched in spring 2015, The One Repo is a platform attempting to address the fragmentation of institutional, subject, and government repositories that are currently available in the world. At present, there are around 4,000 individual repositories available and finding a mechanism that allows for searching all of them at once is just not possible and neither Google nor Google Scholar solves this problem. Mike Taylor from Index Data is hoping to change that situation for the better by constructing a platform that would allow for the creation of a single database/repository that could gather all of the content from the world's repositories and make it available from a single entry point. Furthermore, the intent is to add Open Access journals into the mix as well. The platform is being built upon existing components that are proven to be robust, efficient, and scalable. The Web user- interface will be open to all without registration, and is built from widgets. The project is in the initial testing phase and they have received the endorsement of SPARC-Europe. Following is the lightning interview with Mike about The One Repo.

\section{What motivated you to try to develop a single repository site?}

Partly, it's the most basic of all motivations: I wanted to access a single repository site for my own research work, and there wasn't one. I want to use The One Repo; for that to happen, someone had to build it.

But more importantly, I believe very deeply in Open Access. There is a moral imperative for scholars who create new knowledge to make it available to the whole world, not just to the tiny percentage of a tiny percentage who have access now. Lots of people need access to scholarly research but don't have it: doctors and their patients, parents of children with rare conditions, policy-makers, consumer organizations, fossil preparators, retired or otherwise unaffiliated scholars, teachers, enterprising schoolchildren, commercial research organizations, and so many more. (See Who Needs Access: <http://whoneedsaccess. org/> for some case studies.) Most of all, it's appalling when doctors struggling with medical crises in the developing world can't afford to 
access the most up-to-date literature on the conditions they're trying to treat. Barriers to research cost lives. At the risk of sounding grandiose, The One Repo is really all about fixing that.

\section{What has The OneRepo accomplished up to this point?}

We've been able to move fast, because we're building on top of an existing stack of software generously provided by my employer, Index Data, who are fully behind what we're doing with The One Repo. We have established a database and a harvesting infrastructure, and begun setting up harvesting jobs to populate that database, transforming the harvested data into a canonical format which hides the detailed implementation differences of the harvested repositories. We've set up free access to that database via a Web service, and used that to implement a set of user interface (UI) widgets. We've used those widgets to create the demo UI, so everything we've built on top of the database is done using components that anyone else could have used to do the same. We actively want people to build on our work, and create new value.

Meanwhile, behind the scenes, we've assembled an advisory board of some of the wisest and most experienced people in Open Access. We've also begun a tedious but important process of aligning the metadata schemas of multiple existing projects to allow maximum reuse. We've been talking to a lot of great people, trying to make sure that everything we do is built on consensus and collaboration.

Have you noted many people testing out the demo site?

We don't have analytics set up for the demo UI, but I just ran some numbers on the accumulated server logs, and found 1,825 different IP addresses have accessed it. A very simple analysis suggests that a bit more than 300 of those are robots, so we've perhaps had on the order of 1,500 human visitors.

How do you plan to fund The One Repo going forward?

$\mathrm{Ah}$, that is the big question! We very actively don't want to "monetize" it, as that means putting up barriers and then charging people to lower them. There is not, and will never be, an "exploitation plan." The whole point is to make the world's Open Access articles freely and conveniently available to everyone, and we won't do anything to impede that goal.

So that means we're actively looking for funding from philanthropic organizations who share our vision of creating value for the whole world. That can encompass small seed grants to help us with the development work, and hopefully also larger ongoing grants that will help us to move to production scale.

What are you most proud of in regards to The One Repo?

I think it's too early in the day to be very proud yet! We've got good infrastructure, we've made a good start on acquiring and canonicalising data, and we're in dialogue with a lot of influential people, but there's a long path ahead. When we're fully up and running, the thing we'll be most proud of is playing our part in getting so much of the world's knowledge into the hands of the people who really need it. 